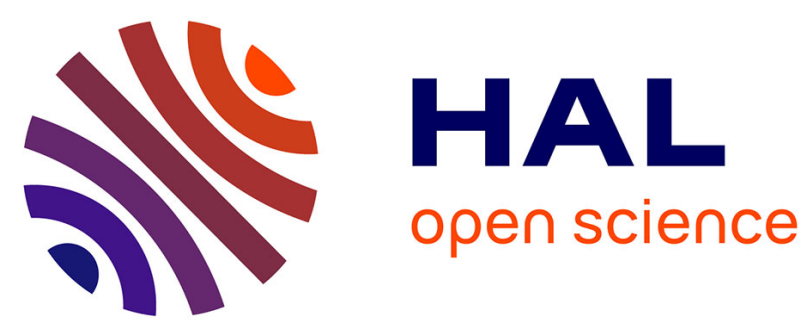

\title{
EFFECT OF IMPURITIES ON THE INTERNAL FRICTION SPECTRUM OF MAGNESIUM AFTER PLASTIC DEFORMATION
}

\author{
S. Seyed Reihani, C. Esnouf, Gilbert Fantozzi, G. Revel
}

\section{- To cite this version:}

S. Seyed Reihani, C. Esnouf, Gilbert Fantozzi, G. Revel. EFFECT OF IMPURITIES ON THE INTERNAL FRICTION SPECTRUM OF MAGNESIUM AFTER PLASTIC DEFORMATION. Journal de Physique Colloques, 1981, 42 (C5), pp.C5-145-C5-150. 10.1051/jphyscol:1981522 . jpa-00221064

\section{HAL Id: jpa-00221064 https://hal.science/jpa-00221064}

Submitted on 1 Jan 1981

HAL is a multi-disciplinary open access archive for the deposit and dissemination of scientific research documents, whether they are published or not. The documents may come from teaching and research institutions in France or abroad, or from public or private research centers.
L'archive ouverte pluridisciplinaire HAL, est destinée au dépôt et à la diffusion de documents scientifiques de niveau recherche, publiés ou non, émanant des établissements d'enseignement et de recherche français ou étrangers, des laboratoires publics ou privés. 


\title{
EFFECT OF IMPURITIES ON THE INTERNAL FRICTION SPECTRUM OF MAGNESIUM AFTER PLASTIC DEFORMATION
}

\author{
S.M. Seyed Reihani, C. Esnouf, G. Fantozzi and G. Reve1* \\ Groupe d'Etudes de Métallurgie Physique et Physique des Matéricaux - E.R.A. \\ 463, Institut National des Sciences Appliquées, Bât. 502, 69621 VilZeurbanne \\ Cedex, France \\ * Laboratoire d'Analyse par activation Pierre Süe, C.E.N. Saclay, France
}

\begin{abstract}
We have studied the impurity effect on the internal friction spectrum, with two different samples magnesium $4 \mathrm{~N}$ and magnesium $6 \mathrm{~N}$ containing zinc and iron :

- for the sample $4 \mathrm{~N}$ we observe a broad peak depending on the oscillation strain amplitude : this peak shifts towards low temperature when the amplitude increases.

- for the sample $6 \mathrm{~N}$ containing zinc and iron, the internal friction spectrum is different form the one of the $6 \mathrm{~N}$ sample previously mentioned. After annealing at $250 \mathrm{~K}$ we observe, at low strain amplitude, besides the $B_{1}$ and $B_{2}$ peaks, two other peaks situated around 100 and $150 \mathrm{~K}$. But at a high strain amplitude we find the two peaks $B_{I}$ and $B_{2}$ as in the $6 \mathrm{~N}$ sample.

After annealing at $500 \mathrm{~K}$ the $\mathrm{B}_{1}$ and $\mathrm{B}_{2}$ peak are not observed but a large peak appears which shifts towards low temperature with increasing $\varepsilon_{\mathrm{m}}$ This peak is specific on thermomechanical unpinning of dislocations.
\end{abstract}

\section{Introduction.- The internal friction spectrum of a high purity magnesium after} Flasticdeformation is very similar to the one observed in f.c.c. metals. Indeed, the broad peak observed for the less pure materials [1-2] is replaced by severa1 peaks in the case of pure magnesium [3-4]. There are :

a) two peaks situated around 40 and $80 \mathrm{~K}$ labelled $\mathrm{B}_{1}$ and $\mathrm{B}_{2}$ respectively. They are stable during annealing.

b) two peaks situated around 105 and $220 \mathrm{~K}$, called $P_{1}$ and $P_{2}$ respectively and removed during temperature cycling.

c) a peak at $15 \mathrm{~K}$ or an important decrease of internal friction between 10 and $30 \mathrm{~K}$ after annealing up to $300 \mathrm{~K}$

d) a stable peak near $420 \mathrm{~K}$

We have shown elsewhere that the two peaks $B_{1}$ and $B_{2}$ have the characteristics of the Bordoni relaxation $[5,6]$ i.e. :

- they are relatively stable during annealing

- their maximum temperature depend weakly on the microstructural state and obeys the Arrhenius relation.

- their relaxation strength presents a maximum as a function of stress behaviour.

In this paper we have studied the impurity effect on the internal friction 
2. Experimental results. - Three differents polycrystalline samples have been used :

- a high purity magnesium noted $\mathrm{Mgl}$ with one at. ppm of impurity $(99,9999 \%)$.

- a less pure magnesium noted $\mathrm{Mg}_{2}$ with < 100 at.ppm of impurity $(99,99 \%)$.

- a high purity magnesium noted $\mathrm{Mg}_{3}$ containing zinc and iron (20 at ppm zinc $+25 \pm 13$ at ppm iron).

After drawing, the samples were annealed for two hours at $300^{\circ} \mathrm{C}$ under argon atmosphere (grain size $\simeq 1 \mathrm{~mm}$ ). The internal friction have been performed with an inverted torsion pendulum oscillating at a frequency of about $1 \mathrm{~Hz}$, with a maximum strain amplitude equal to $410^{-5}$. The specimens have been deformed in situ by torsion of $2 \%$ at $10 \mathrm{~K}$ then the internal friction was recorded between $10 \mathrm{~K}$ and 500 during 1 inear heating at a rate of $60 \mathrm{k} / \mathrm{h}$. Fig. 1, 2 and 3 show the internal friction spectra as a function of temperatrue between 10 and $250 \mathrm{~K}$, for the three samples $\mathrm{Mg} 1$ and $\mathrm{Mg} 2$ and $\mathrm{Mg}_{3}$.

Immediately, after plastic deformation at $10 \mathrm{~K}$ (fig.1), we observe :

- for the $\mathrm{Mg}_{1}$ sample (curve 1) : two small peaks $\mathrm{B}_{1}$ and $\mathrm{B}_{2}$ situated around 40 and $80 \mathrm{~K}$, and an important peak $\mathrm{P}_{1}$ situated around $105 \mathrm{~K}$. Furthermore we observe a peak $\mathrm{P}_{2}$ situated about $220 \mathrm{~K}$.

- for the $\mathrm{Mg}_{3}$ sample (curve 3) : there are a relatively large peak at about $40 \mathrm{~K}$ and a peak (may be $\mathrm{P}_{\mathrm{I}}$ ) at about $105 \mathrm{~K}$.

- for the Mg2 sample (curve 2) : there is a large maximum situated between 30 and $120 \mathrm{~K}$.

It must be noted that the internal friction background is important for $\mathrm{Mg}_{2}$ and. $\mathrm{Mg}_{3}$ samples.

After heating up to $250 \mathrm{~K}$ (fig.2) we observe essentially :

- for $\mathrm{Mg}_{1}$ sample, two peaks $\mathrm{B}_{1}$ and $\mathrm{B}_{2}$ at about 40 and $80 \mathrm{~K}$ and a small peak $\Pi_{1}$ at about $15 \mathrm{~K}$ (curve 1 ).

- for $\mathrm{Mg}_{3}$ sample (curve 3) two small peaks (may be $\mathrm{B}_{1}$ and $\mathrm{B}_{2}$ ) at about 40 and $65 \mathrm{~K}$, but the internal friction background is relatively strong.

- for $\mathrm{Mg}_{2}$ sample (curve 2) always a large maximum is present between 40 and $120 \mathrm{~K}$ and also the internal friction background is very important (we can compare the internal friction at $150 \mathrm{k}$ for the three samples).

Fig. 3 presents the internal friction spectra after annealing at $400 \mathrm{~K}$ for the three samples; one can note:

- for the $\mathrm{Mg}_{1}$ sample (curve 1), the two peaks $\mathrm{B}_{1}$ and $\mathrm{B}_{2}$ have disappeared and an important decrease of the internal friction is noticed between $10 \mathrm{~K}$ and $30 \mathrm{~K}$, the pic $\Pi_{1}$ being annealed.

- for the $\mathrm{Mg}_{2}$ and $\mathrm{Mg}_{3}$ samples, we observe a relatively large maximum at about $40 \mathrm{~K}$ (for $\mathrm{Mg}_{3}$; curve 3 ) and $25 \mathrm{~K}$ (for $\mathrm{Mg}_{2}$, curve 2). The internal friction background is more elevated for the $\mathrm{Mg} 2$ sample than $\mathrm{Mg}_{3}$ and especially an increase of the internal friction background is observed at about $150 \mathrm{~K}$ for $\mathrm{Mg} 2$ sample.

We have shown elsewhere [6] that the internal friction background is very sensitive to the oscillating strain amplitude $\varepsilon_{\mathrm{m}}$. In order to eliminate the internal 
background effect we have measured the internal friction at a small amplitude (some $10^{-6}$ ). The fig. 4 shows the internal friction spectrum of the $\mathrm{Mg}_{3}$ sample after plastic deformation at $10 \mathrm{~K}(2 \%)$ and annealing at $250 \mathrm{~K}$.

On this figure one can note that besides the $\mathrm{B} \cdot 1$ and $\mathrm{B}_{2}$ peaks, two other peaks situated around $100 \mathrm{~K}$ and $145 \mathrm{~K}$ appear. One peak seems to shift to lower temperature with increasing the strain amplitude.

After heating upto $500 \mathrm{~K}$ (the $\mathrm{B}_{1}$ and $\mathrm{B}_{2}$ peaks have been already disappeared) we have studied the variation of the internal friction as a function of the strain amplitude $\left(\varepsilon_{m}\right)$ for different temperatures (Fig. 5). The curves $\delta=f\left(\varepsilon_{m}\right)$ shift towards low temperature with increasing the measurement temperature (curve 1 to 4 ) and the internal friction maximum has about the same value.

3. Discussion.- Wa have shown elsewhere that the $B_{1}$ and $B_{2}$ peaks observed in a high purity magnesium after plastic deformation have the same features as the Bordoni relaxation in the f.c.c. metals.

For a less pure magnesium, the internal friction spectrum is constituted of a large maximum between 40 and $120 \mathrm{~K}$ (fig. 1 and 2 ). This maximum has been observed by several authors in a less pure magnesium [1,2]. In a magnesium $6 \mathrm{~N}$ containing zinc and iron, at a low measurement amplitude, we observe besides the Bordoni peakssome other peaks (Fig.4). We can consider then, the large maximum observed in a less pure magnesium can be the superposition of two or more peaks. This idea has been already proposed by Tsui and Sack. This maximum shifts towards lower temperature when measurement amplitude $\varepsilon_{\mathrm{m}}$ increases [6]. Thus, this maximum can be attributed to a thermally activated breakaway process and we try to analyse the results by the T.G.L. depinning model.

Teutonico et al [7] have developed a model for thermally activated brea.kaway of a dislocations with only one pinned point at its middle. This dislocation have one or two equilibrium position according to the value of the applied stress or the dislocation loop length 21.

- for the loop length smaller than critical length $1_{c}=\frac{2 G b^{4}}{E_{o}}$ only the pinned position of dislocation is possible. ( ${ }_{o}$ : activation energy for the depinning).

- for the loop length larger than $l_{c}$, there are two equilibrium position of dislocation; one corresponding to pinned position and another one corresponding to the depinning position.

In the case of a high frequency or a low temperature $\left(\mathrm{E}_{0}>\mathrm{kT}\right)$ and considering an exponential distribution of the loop lengths, Lücke et al [8] lead to a simplified form of the internal friction as a function of a parameter $\tau$ determined by the applied stress, the temperature and the frequency.

$$
\begin{aligned}
\Delta \tau & =\Lambda \mathrm{L}^{2}\left(\frac{1+\tau}{\tau^{3}}\right) \exp -\left(\frac{1}{\tau}\right) \\
\tau & =\frac{\mathrm{L}}{1_{0}}=\frac{\sigma_{0}}{\sigma_{\mathrm{t}_{1}, L}}
\end{aligned}
$$


$I$ : the average loop length of dislocation.

$1_{\mathrm{Q}}$ : the critica1 loop length and
$\sigma_{\mathrm{T}_{1}, \mathrm{~L}}=\sigma_{1}\left\{1-\left[\frac{\mathrm{kT}}{\mathrm{E}_{0}} \ln \left[\left(\frac{v_{1} \sigma_{1}}{8 \nu \sigma_{0}}\right) \frac{\mathrm{kT}}{\mathrm{E}_{0}}\right]\right]^{1 / 2}\right\}$

$\sigma_{1} \simeq \frac{E_{0}}{b^{2} L}, \quad\left(\nu_{1}\right.$ : the attempt frequency ; $b^{2} L$ : activation volume $)$.

For a given internal friction we have :

$$
\sigma_{m}=\alpha \frac{E_{0}}{b^{2} L} \quad\left(1-\frac{T}{T_{c}}\right)^{1 / 2}
$$

with $\alpha=0,36$ at the maximum. $T_{c}$ is a constant and has a classical value as [9] $\mathrm{T}_{\mathrm{c}} \simeq \mathrm{E}_{\mathrm{o}} / 25 \mathrm{k}$.

For calculating $T_{c}$ and $E_{0}$ the curves of measurement amplitude $\varepsilon_{m}$ has been plotted as a function of $\mathrm{T}^{1 / 2}$ on the figure 6 for a $\mathrm{Mg}_{3}$ sample after annealing at $500 \mathrm{~K}$. From this figure, considering the relation (II) we can get :

$$
\begin{aligned}
& \mathrm{T}_{\mathrm{c}}=75 \mathrm{~K} \text { and as } \mathrm{T}_{\mathrm{c}} \simeq \mathrm{E}_{\mathrm{o}} / 25 \mathrm{~K} \text {, we have: } \\
& \mathrm{E}_{\mathrm{o}}=0,16 \pm 0,02 \mathrm{eV} ; \mathrm{b}^{2} \mathrm{~L} \simeq 200 \mathrm{~b}^{3}
\end{aligned}
$$

Using an Arrhenius relation $f=f_{0}$ exp. $\frac{-E}{k T}$ for the results obtained by frequency change we get $\left(\varepsilon_{m}=2.10^{-5}\right)$ 


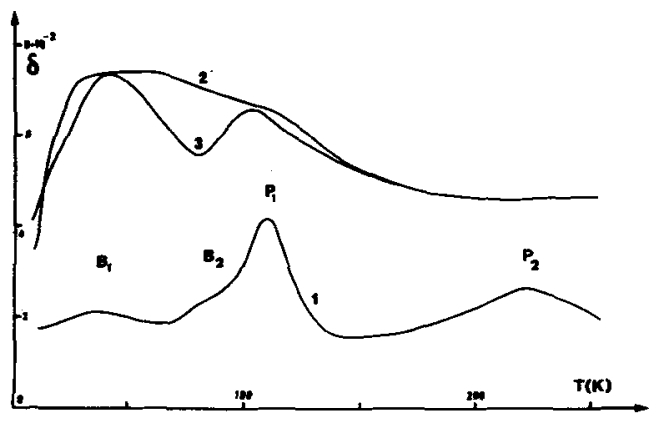

Fig. 1 : Internal friction spectrum for three samples immediately after plastic deformation of $2 \%$ at $10 \mathrm{~K}$.

$\mathrm{Mg}_{1}$ (curve 1, $\varepsilon_{\mathrm{m}}=410^{-5}$ )

$\mathrm{Mg}_{2}$ (curve 2, $\varepsilon_{\mathrm{m}}^{\mathrm{m}}=210^{-5}$ )

$\mathrm{Mg}_{3}$ (curve $3, \varepsilon_{m}^{m}=210^{-5}$ )

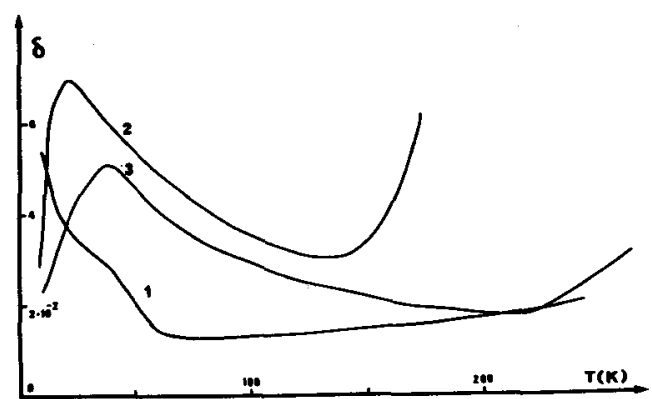

Fig. 3 : Internal friction spectrum after plastic deformation of $2 \%$ at $10 \mathrm{~K}$ and annealing at $400 \mathrm{~K}$

$\mathrm{Mg}_{1}$ (curve 1)

$\mathrm{Mg}_{2}$ (curve 2)

$\operatorname{lig}_{3}$ (curve 3)

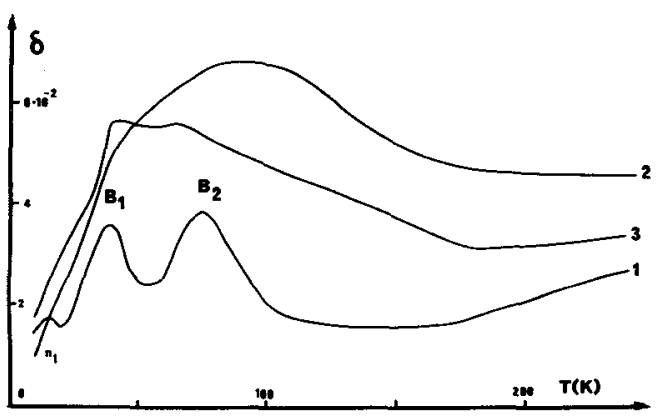

Fig.2 : Internal friction spectrum after plastic deformation of $2 \%$ at $10 \mathrm{~K}$ and heating up to $250 \mathrm{~K}$

Mg1 (curve 1)

$\mathrm{Mg}_{2}$ (curve 2)

$\mathrm{Mg}_{3}$ (curve 3)

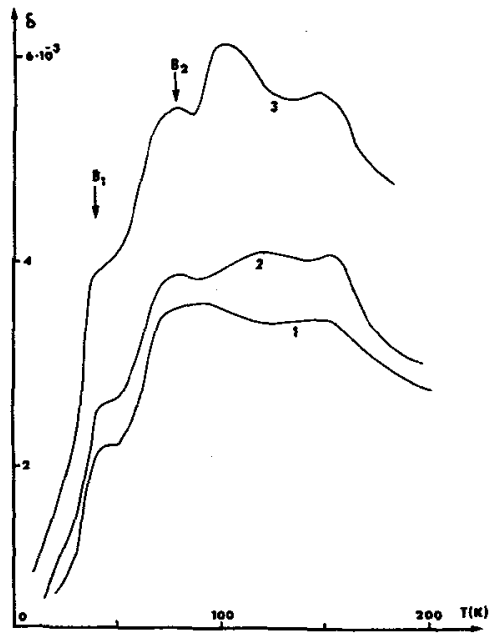

Fig.4 : Internal friction spectrum after plastic deformation of $2 \%$ at $10 \mathrm{~K}$ and annealing at $250 \mathrm{~K}$ for a $\mathrm{Mg}_{3}$ sample with $\varepsilon=3.510^{-6}(1)$

$\varepsilon_{\mathrm{m}}^{\mathrm{m}}=5.810^{-8}$

$\varepsilon_{\mathrm{m}}=1.3610^{-5}$ 

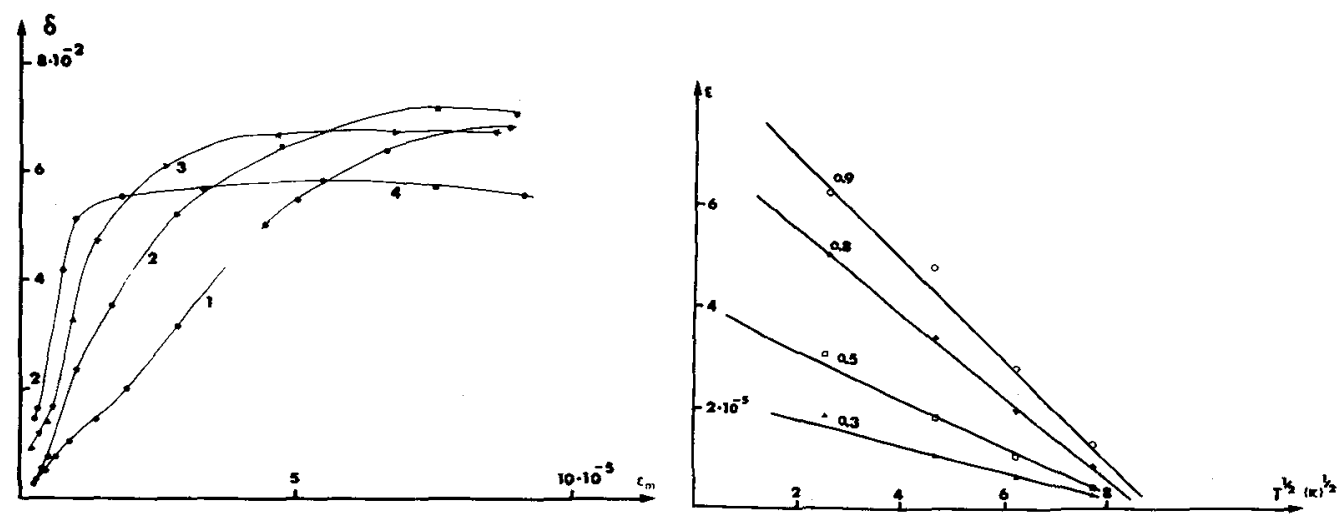

Fig.5 : Internal friction as a function of for a $\mathrm{Mg}_{3}$ sample, after plastic defor- amplitude as a
mation of $2 \%$ at $10 \mathrm{~K}$ and annealing at $500 \mathrm{~K}$ T.G.L. model). Fig. 6 : The variation of measurement 